\title{
Parasite dynamics in untreated horses through one calendar year
}

\author{
Ashley E. Steuer ${ }^{1 *}$, Haley P. Anderson², Taylor Shepherd ${ }^{3}$, Morgan Clark ${ }^{3}$, Jessica A. Scare ${ }^{4}$, Holli S. Gravatte ${ }^{5}$ and \\ Martin K. Nielsen ${ }^{5}$
}

\begin{abstract}
Background: Horses are host to a plethora of parasites. Knowledge of the seasonality of parasite egg shedding and transmission is important for constructing parasite control programs. However, studies describing these patterns are sparse, and have largely been conducted only in the United Kingdom. This study evaluated strongylid egg shedding patterns and transmission dynamics of Strongylus vulgaris in naturally infected and untreated mares and foals through one calendar year in Kentucky, USA. The study also investigated the existence of a peri-parturient rise (PPR) in strongylid egg counts in foaling mares and collected information about Strongyloides westeri and Parascaris spp. in the foals.

Methods: This study was conducted from January to December 2018. A herd of 18 mares, one stallion, and 14 foals born in 2018 were followed throughout the year. Sera and feces were collected biweekly from all horses, and worm burdens enumerated in 13 foals at necropsy. An S. vulgaris ELISA antibody test was run on all serum samples. Fecal egg counts were determined for all horses, and coproculture and qPCR assay were employed to test for the presence of S. vulgaris in the mature horses. Data were analyzed using the proc glimmix procedure in the SAS 9.4 software program.
\end{abstract}

Results: We found a general lack of seasonality in strongylid egg shedding throughout the year among the mature horses, and no PPR was demonstrated. Shedding of S. vulgaris eggs displayed a higher abundance during the spring, but findings were variable and not statistically significant. Anti-S. vulgaris antibody concentrations did not display significant fluctuations in the mature horses, but evidence of passive transfer of antibodies to the foals was demonstrated, and foals assumed their own production of antibodies starting at approximately 20 weeks of age. Overall, colts shed higher numbers of strongylid, ascarid, and S. westeri eggs than fillies.

Conclusions: This study demonstrated a lack of seasonality in strongylid egg shedding for the study population, which is in stark contrast to previous studies conducted elsewhere. This strongly suggests that more studies should be done investigating these patterns under different climatic conditions.

Keywords: Horses, Strongyle, Strongylus vulgaris, Cyathostomin, Seasonality, Serology

\section{Background}

Equine strongylid parasites are ubiquitous around the world. Widespread anthelmintic resistance is reported in these parasites [1], and more information about their seasonality and epidemiology is needed to assist in

\footnotetext{
*Correspondence: ashley.steuer@ttu.edu

1 School of Veterinary Medicine, Texas Tech University, Amarillo, TX, USA

Full list of author information is available at the end of the article
}

determining appropriate approaches for parasite control. The Strongylidae family in equids comprises two subfamilies: Cyathostominae (cyathostomins, small strongyles) and Strongylinae (strongylins, large strongyles). Cyathostomins are commonly reported to show anthelmintic resistance to all currently available drug classes [1, 2], whereas the group of Strongylinae, which includes the bloodworm Strongylus vulgaris, has not been reported resistant to anthelmintic products. original author(s) and the source, provide a link to the Creative Commons licence, and indicate if changes were made. The images or other third party material in this article are included in the article's Creative Commons licence, unless indicated otherwise in a credit line to the material. If material is not included in the article's Creative Commons licence and your intended use is not permitted by statutory regulation or exceeds the permitted use, you will need to obtain permission directly from the copyright holder. To view a copy of this licence, visit http://creativecommons.org/licenses/by/4.0/. The Creative Commons Public Domain Dedication waiver (http://creativecommons.org/publicdomain/zero/1.0/) applies to the data made available in this article, unless otherwise stated in a credit line to the data. 
Strongylus vulgaris is widely regarded as the most pathogenic intestinal helminth parasite in horses [3, 4]. With the advent of modern anthelmintics in the 1960s, an interval dose approach was introduced with a primary aim to control this parasite in equine herds [5]. Frequent anthelmintic treatments administered at regular intervals year-round significantly reduced the prevalence of S. vulgaris, and cyathostomins subsequently became the focus of parasite control $[6,7]$. However, these decades of intense anthelmintic treatment regimens also led to widespread drug resistance among cyathostomins $[1,2]$. Because of this development, current recommendations aim to adopt surveillance-based parasite control programs and reduce anthelmintic treatment intensities to delay further resistance development as much as possible [8-10].

While the development and survival of free-living stages of the life-cycle is well described for all strongylid parasites and has been demonstrated to be dependent on weather, season, and climate $[11,12]$, the parasitic phases differ substantially between cyathostomins and strongylins. Larvae of $S$. vulgaris migrate in the mesenteric arteries for about 4 months before they return to the intestinal tract and reach sexual maturity at about 6 months of age [13]. In comparison, some cyathostomin parasite species can complete their life-cycle in 6-8 weeks [14], but encysted early third stage larvae (EL3) can undergo arrested development for at least 2 years [15-17]. Thus, epidemiological patterns likely differ substantially between cyathostomins and $S$. vulgaris.

Despite the recognized importance of equine strongylid parasites and the emphasis on surveillance-based approaches to controlling them, a limited number of studies have been published on seasonal patterns of strongylid transmission dynamics in equines, and the majority of these have been conducted in the United Kingdom (UK). In 1954, Poynter [18] was the first to describe seasonality in equine strongylid egg shedding, and reported egg counts to be lowest in the winter and highest during July, August, and September. This was followed up by Duncan in 1974 [11], who also described a seasonal pattern in strongylid egg shedding, with counts increasing during the spring and subsequently plateauing during summer. In the past decade two British studies have been published, with one finding similar seasonal egg shedding patterns [19], while the other found no evidence of such seasonality among adult horses [20]. Recently, a Swedish 2.5-year study of free-ranging ponies found strongylid fecal egg counts (FECs) to peak in August/September [21], and a New Zealand study reported broodmares to exhibit lower strongylid FECs during winter months [22], both confirming Poynter's observations from almost 70 years ago. One study performed in ponies in Louisiana, USA, reported significantly lower mean strongylid FECs during winter months, but these were data from ponies that were euthanized at different time points, and repeated measures were not done across seasons [23]. Taken together, strongylid egg shedding patterns have not been investigated widely, and very few studies have been reported from outside of the UK.

Strongylid egg shedding patterns have been documented to be influenced by a variety of factors including age, sex, and pasture management. Young horses (1-4 years) have shown elevated strongyle egg shedding patterns $[19,20,24]$, while middle aged horses (5-15 years) often display the lowest strongyle egg output [24], and older horses (20-33 years) have been shown to have higher strongyle egg counts $[24,25]$. A few studies have found different strongylid egg count levels between male and female horses, but results are conflicting. One study reported higher strongylid FECs in 2-4-year-old domesticated males [24], while a study of feral horses found that males displayed lower strongylid FECs in some locations [26]. A peri-parturient rise (PPR) in strongylid egg shedding has been widely documented in sheep $[27,28]$; however, Duncan investigated this phenomenon among nine foaling mares and did not observe any fluctuations [11]. There are no other published studies evaluating the possible existence of a PPR in horses, so more research is warranted before any clear conclusions can be drawn.

Duncan also documented a seasonal pattern in S. vulgaris egg shedding density, with elevated coproculture larval counts during the spring and summer compared to the remainder of the year [11], but the seasonality of this parasite has not been widely studied since then. One study evaluated the seasonality and distribution of $S$. vulgaris in foals and documented passive transfer of maternal anti-S. vulgaris antibodies [29]. Although it can be assumed that the concentration of these maternal antibodies is a function of the serum antibody concentration of the accompanying dam, this relationship has not been investigated at this stage.

The overall aim of this study was to characterize the seasonality of strongylid type egg shedding over the course of one calendar year in a herd maintained without anthelmintic treatment in central Kentucky, USA. Additional aims were to (1) investigate the possible existence of PPR in foaling mares, (2) describe the seasonality of $S$. vulgaris egg shedding and serum antibody responses in mares and foals, (3) characterize the relationship between anti-S. vulgaris antibody concentrations in foals and their dams over the course of the year, (4) determine Strongyloides westeri and Parascaris spp. egg shedding in the foals, and (5) document adult and 
larval strongylid and ascarid worm burdens in necropsied foals from the herd.

\section{Methods \\ Study population}

This study was conducted from January to December of 2018 in central Kentucky, USA, a warm temperate, fully humid, hot summer climate (Cfa), based on the KöppenGeiger climate classification system. Horses from the University of Kentucky's anthelmintic naïve parasitology herd were evaluated under the University of Kentucky's Institutional Animal Care and Use Committee protocol 2012-1046. This closed herd had not received anthelmintics and has been located on the same grazing pasture since 1979 [30]. Horses were provided free access to pasture, hay, and mineral blocks, and were fed a ration balanced grain supplement over the course of the study. Two age groups were defined within this herd: a mature horse population with ages of $7-18$ years $(n=19,18$ mares and one stallion) and foals born into the herd in 2018 and followed until necropsy at 4-8 months of age. All mares were bred in the field via live cover in 2017. Foals $(n=14$; 9 fillies, 5 colts) were born between April and July 2018, and 13 of these were euthanized either at 4-6 months of age $(n=9)$ or at $6-8$ months of age $(n=4)$.

\section{Fecal and serum sample collection}

Samples were collected biweekly from all mature horses and weekly/biweekly from the foals, depending on the behavior of the individual animals. Fecal samples were collected from fresh droppings or manually from the rectum. Serum samples were collected by venipuncture of the jugular vein(s) of each animal. Fecal samples were immediately packaged, labeled, and stored at $4{ }^{\circ} \mathrm{C}$ for further laboratory processing, and serum samples were stored at $-80^{\circ} \mathrm{C}$ until processing.

\section{Fecal egg counts}

FECs were determined in triplicate using the Mini-FLOTAC method as described previously [31], using a saturated glucose- $\mathrm{NaCl}$ flotation medium (specific gravity of 1.25) and with a multiplication factor of five eggs per gram (EPG). Specimens were evaluated for strongylid, Parascaris spp., and S. westeri type eggs. However, due to an abundance of $S$. westeri in the foal samples, $S$. westeri egg counting was discontinued after a threshold of 5000 EPG was reached.

\section{Coproculture and larval strongylid differentiation}

Individual coproculture was carried out for all mature horses upon each collection, using $10 \mathrm{~g}$ of fecal matter and an equal amount of vermiculite to promote water retention and aeration, as described previously [32].
Samples were incubated at room temperature for 14 days and then placed in a Baermann apparatus for an additional 2 days. The entire sediment was harvested, and larvae were stored at $4{ }^{\circ} \mathrm{C}$ until identification. For identification, larvae were transferred to nematode counting slides and subsequently heat-inactivated by placing the nematode counting slide on a warming plate at $60{ }^{\circ} \mathrm{C}$ for $5 \mathrm{~min}$, or until small bubbles formed. Samples were then examined microscopically at $\times 10$ magnification, and third-stage larvae were counted up to 500. Larvae were identified to genus and/or species using a published key [33].

\section{Strongylus vulgaris qPCR}

Eggs were isolated from fecal samples via egg isolation methods described previously [34]. Briefly, $10 \mathrm{~g}$ of feces was mixed with $50 \mathrm{ml}$ of tap water. The mixture was strained through a two-ply cheesecloth $(18 \times 36$ in., grade 10 mesh, Fisher Scientific, Waltham, MA, USA) and centrifuged for $10 \mathrm{~min}$ at $300 \times g$. The pellet was then suspended in $50 \mathrm{ml}$ of glucose- $\mathrm{NaCl}$ flotation solution $(\mathrm{SG}=1.25)$ and centrifuged again at $300 \times g$ for $10 \mathrm{~min}$. The supernatant containing the eggs was then subjected to straining through a series of filters arranged by filter size (largest to smallest: $200 \mu \mathrm{m}, 100 \mu \mathrm{m}$, and $27 \mu \mathrm{m}$ ) (pluriSelect Life Science, Leipzig, Germany). Isolated eggs were then retrieved from the $27 \mu \mathrm{m}$ filter and stored in $100 \% \mathrm{EtOH}$ at $-20{ }^{\circ} \mathrm{C}$ until DNA isolation. Ethanol was removed from egg samples prior to DNA extraction via evaporation. The Quick DNA Fecal/Soil Microbe kit (Zymo Research, Irvine, CA, USA) was used to isolate DNA from egg samples according to the protocol provided by the manufacturer. Real-time polymerase chain reaction (qPCR) assay was used to identify $S$. vulgaris DNA in isolated eggs as described previously [35]. A mixture of Brilliant II QPCR Master Mix (Agilent Technologies, Santa Clara, CA, USA) and $4 \mu$ of extracted DNA was used, and the temperature and cycles were set as described previously [35]. Primers and probes were obtained from Integrated DNA Technologies (Skokie, IL, USA), and concentrations were set as described previously [35]. Positive controls for the assay were obtained from an adult morphologically identified S. vulgaris specimen. For statistical analysis, all negative PCR reactions were recorded as a cycle threshold (Ct) of 100 .

\section{Strongylus vulgaris ELISA}

Serum samples were measured for concentration of antibodies specific to the SvSXP antigen produced by migrating $S$. vulgaris larvae using an enzyme-linked immunosorbent assay (ELISA) as described previously [36]. All samples were diluted 1:50 with phosphate-buffered saline solution with Tween (PBST) (1:10 dilution), 
and a secondary antibody of horseradish peroxidase conjugated to goat anti-horse IgG(T) (Bethyl Laboratories, Inc., Montgomery, TX, USA) at a dilution of 1:40,000 was added to each well. Results were normalized as a percentage of the positive control to reduce inter-assay variability [36]. The positive control sample was obtained from a horse known to be infected with $S$. vulgaris.

\section{Necropsy procedures}

The foals were divided into two groups based on a previously reported biphasic appearance of ascarid worm burdens and egg shedding [37, 38], with nine foals (7 fillies, 2 colts) euthanized at the presumed peak ascarid burden age (4-6 months) and four foals ( 1 filly, 3 colts) euthanized at 6-8 months of age. Necropsy procedures followed previously published principles [39], and the following parasite species and stages were collected and enumerated. Attempts were not made to obtain specimens of $S$. westeri from the small intestines, as egg shedding patterns had indicated that populations of $S$. westeri were eliminated prior to euthanasia.

\section{Cyathostomins}

Encysted larval stages were enumerated for each of the large intestinal sections-cecum, ventral colon, and dorsal colon-using a mucosal digestion technique as described previously [40], and larvae identified to either early third stage (EL3) or developing stages [late thirdstage (LL3) and mucosal fourth-stage larvae (L4)]. A multiplication factor of 500 per organ was used to estimate the total mucosal burden of each organ.

Luminal cyathostomin stages were enumerated for each large intestinal organ by examining a subsample representing a $1 \%$ aliquot of the total content volume and subsequently multiplying the count by 100 to estimate the total luminal cyathostomin burden for each foal.

\section{Strongylus spp.}

The cranial mesenteric (CMA) and celiac arteries were dissected, and migrating stages of S. vulgaris were collected and morphologically identified to stage (L4 and L5) and sex (L5 only). Similarly, the ventral abdominal walls and peri-renal fat tissues were inspected and dissected for the presence of migrating $S$. edentatus larvae, which were identified to stage (L4 and L5) and sex (L5 only) as well. Intestinal Strongylus spp. specimens were collected from the cecum, ventral colon, and dorsal by visual inspection of mucosal walls for attached parasites and macroscopical examination of the entire intestinal content.

\section{Other parasites}

Parascaris spp. specimens were collected by visual inspection of the entire small intestinal tract and by examining the intestinal contents from the large intestines. Specimens were identified to L4 or L5 (male and female), where appropriate. Ascarids in this documented herd have been karyotyped previously and identified as P. univalens [41], but karyotyping was not carried out in this study, so findings are reported as Parascaris spp. herein. Anoplocephala perfoliata were collected by inspection of the cecal mucosal walls and examination of the intestinal contents from the large intestines.

\section{Statistical analyses}

McNemar's test was run comparing the qualitative results obtained with the coproculture and qPCR using online software (www.graphpad.com). All statistical models were run with SAS University edition software (Cary, NC, USA), and were analyzed with generalized mixed linear models using the glimmix procedure, with a Gaussian distribution assumed. Akaike information criterion and Akaike information criterion corrected were used to assess model fit. JMP Pro 14 software (Cary, NC, USA) was used to create figures and estimate confidence intervals and correlations. Associations of all measured parameters for each analysis was evaluated using traditional backward and forward elimination of variables. All variables with $P$-values $<0.25$ were kept in the model. When variables were significant, a least-square means for Tukey's pairwise comparison, odds ratio, and estimate were all performed, and interpretation of results carried out at a significance level $\alpha=0.05$.

\section{Mature horses}

Mature horses were categorized based on age, sex, egg shedding category, and parturition status. At each collection time point, horses were assigned to the following egg shedding categories: low shedders (0-99 EPG), moderate shedders (100-499 EPG), and high shedders (>500 EPG). Furthermore, the horses were assigned to one of two age categories: 7-11 years $(n=7)$ and $12-18$ years $(n=12)$. Each sample collection time point was assigned a corresponding collection number (1-24) and season: winter (December-February), spring (March-May), summer (June-August), and autumn (September-November). At each time point, mares were assigned a parturition status of either 0 (no foal) or 1 (foal). Models were constructed with FEC, ELISA, PCR, and coproculture results (\% S. vulgaris and total $S$. vulgaris larvae counted) as outcome variables and with 
age, season, collection date, and parturition as input variables. "Horse_ID" was kept as a random effect, and repeated measures used with collection date, where appropriate.

\section{Foals}

In foals, $S$. vulgaris ELISA, FEC (strongylid, ascarid, $S$. westeri), and worm counts (S. vulgaris, S. edentatus, cyathostomins, Parascaris spp.) were analyzed as output variables. In addition to the ELISA values determined at each time point, a foal/mare ELISA ratio variable was created for each foal at each time point as the ratio between the ELISA value in the foal at the time of determination divided by the ELISA value of the corresponding dam at the time of parturition. Models were constructed analyzing these output variables with age, sex, or time point evaluated as input variables. "Horse ID" was kept as a random effect, and repeated measures used with collection date, where appropriate.

\section{Results}

Mature horse fecal egg counts

Mean mature horse strongylid egg counts are presented in Fig. 1. There were no statistical associations between mean strongylid FECs and age groups, seasons, collection dates, or parturition status among the mature horses.

\section{Foal fecal egg counts \\ Strongylids}

For strongylid egg shedding, eggs were first detected in the feces at 1 week of age (Fig. 2). There was a small peak around 6 weeks of age, followed by an increase over time in both colts and fillies $(P=0.0163)$. Colts had a higher peak at6 weeks and a higher count overall $(P=0.0152$, Fig. 2). Overall, older foals shed significantly higher numbers of eggs, and higher strongylid shedding occurred in the winter than during other seasons $(P=0.0208)$. There was also a significant association with the interaction terms age $\times$ season and age $\times$ sex, where older foals and colts shed more in the winter season versus other seasons $(P=0.0437)$.

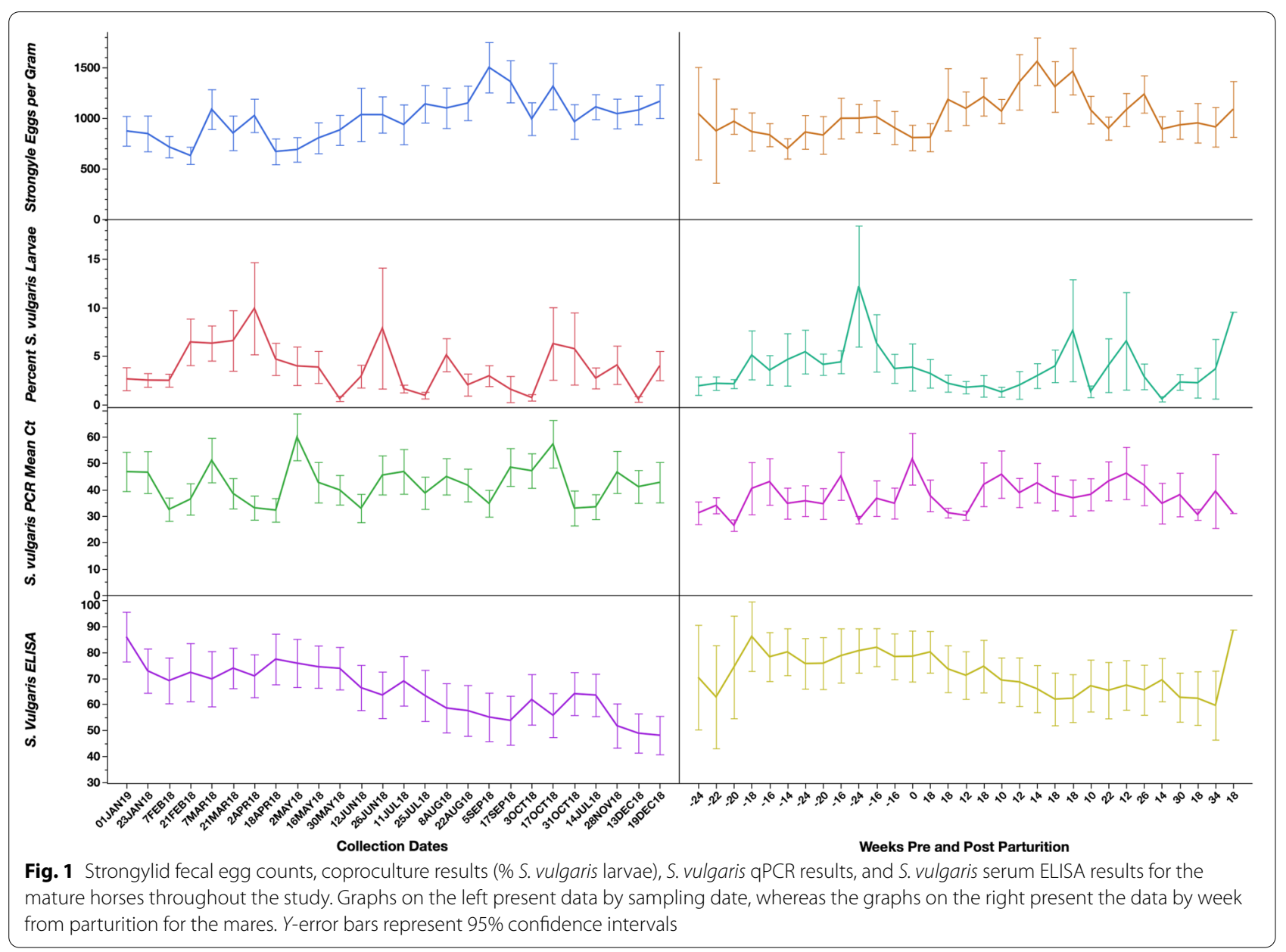




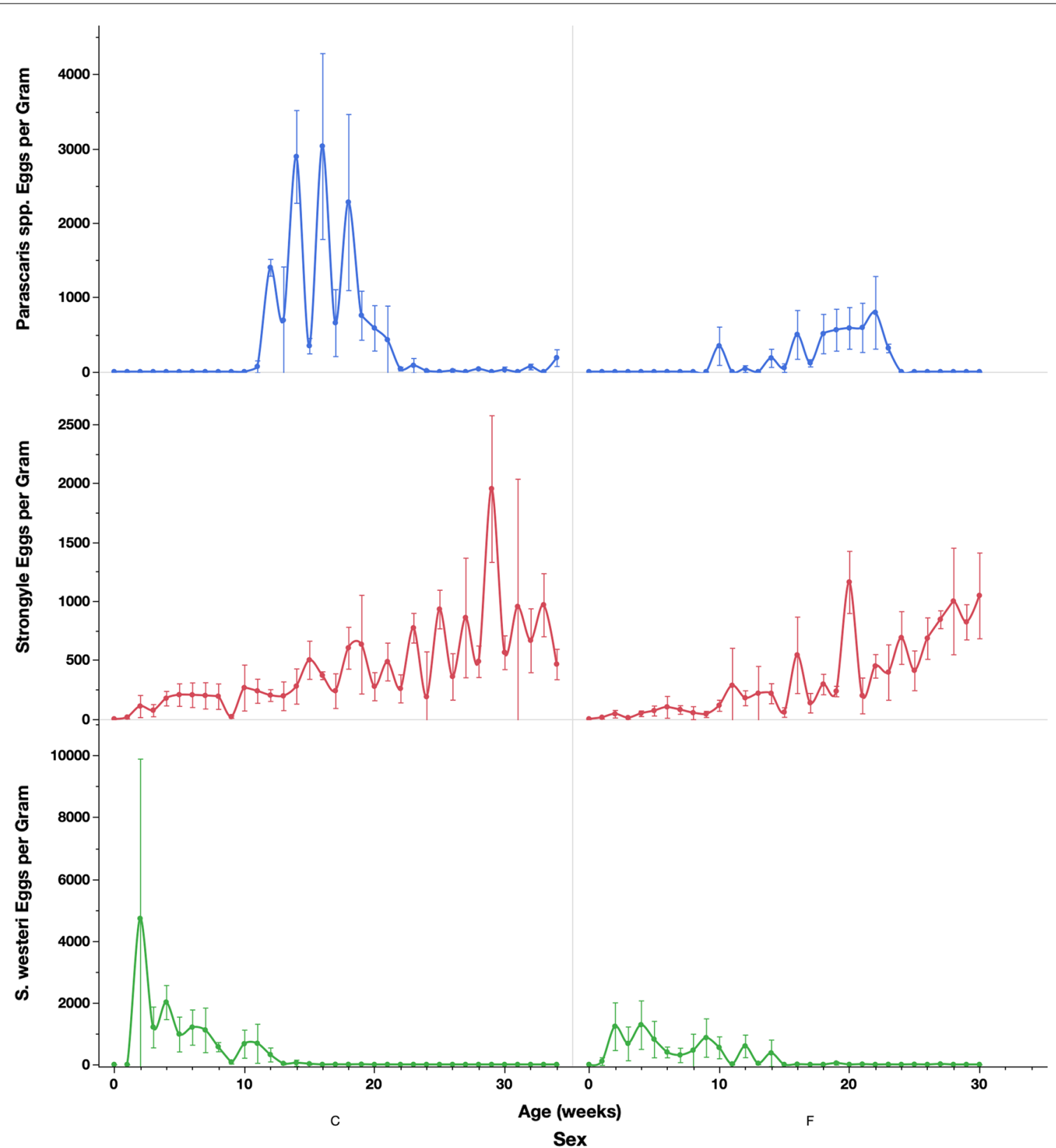

Fig. 2 Parascaris spp., strongylid, and S. westeri fecal egg counts in the foals across the weeks of the study. Graphs on the left present data for the colts, while graphs on the right present data for the fillies. Y-error bars represent $95 \%$ confidence intervals

\section{Parascaris spp.}

Fecal Parascaris spp. shedding started at 6 weeks of age and continued through 37 weeks (Fig. 2). Colts had higher egg shedding than fillies, and peak shedding occurred at 16 weeks for the colts compared to 22 weeks for the fillies; however, this was not statistically significant. When considering age and season, the FECs were significantly higher during the autumn compared to winter, after accounting for the influence of age $(P=0.0351)$.
Fillies shed eggs earlier and for a longer duration (1124 weeks) compared to colts, which shed higher numbers but for a shorter period (10-21 weeks).

\section{Strongyloides westeri}

Age, season, age $\times$ season, and age $\times$ sex were all significantly associated with S. westeri egg shedding (Fig. 2). Peak $S$. westeri shedding occurred at 2 weeks of age and subsequently declined throughout the study; however, 


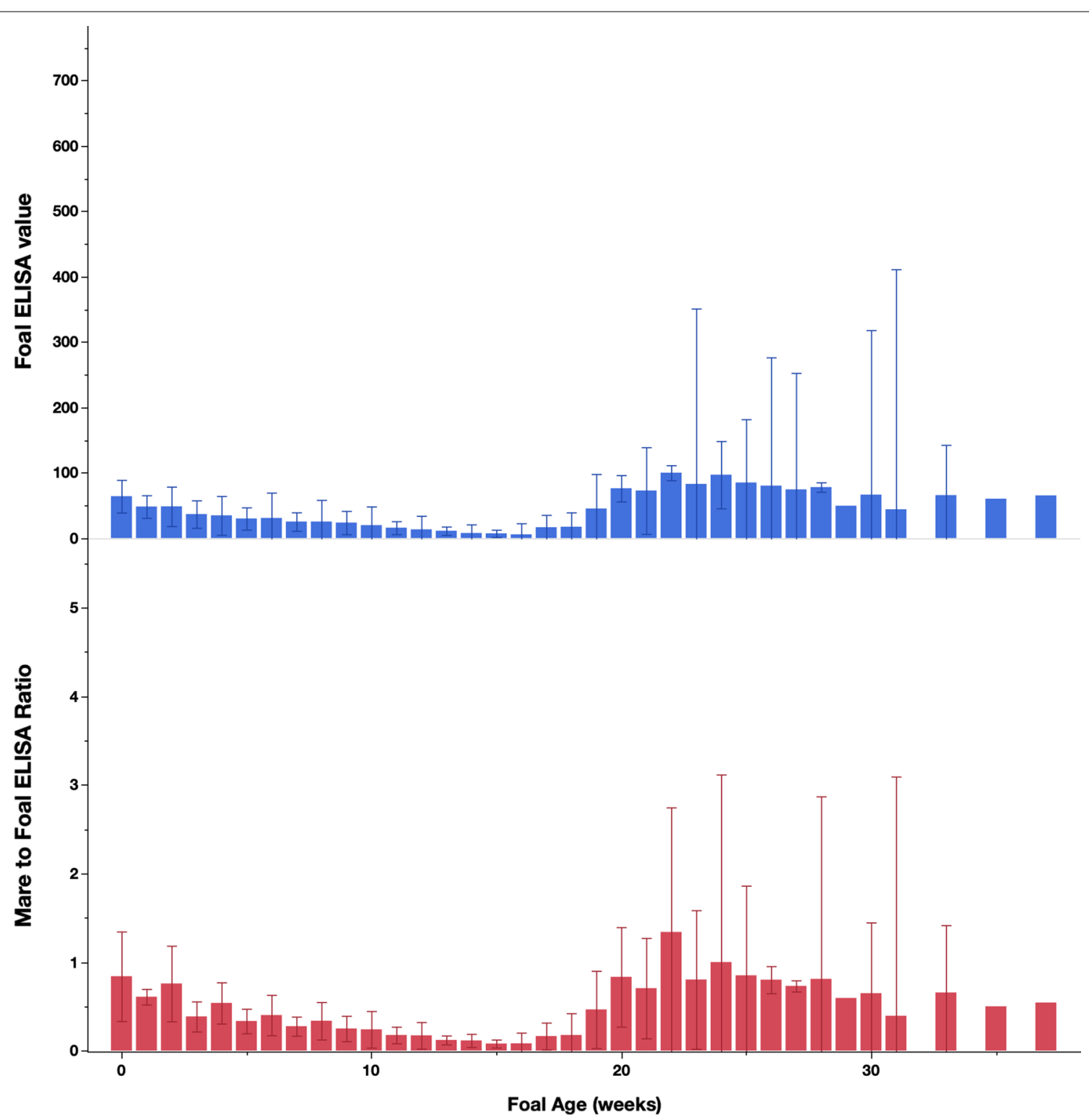

Fig. 3 Serum S. vulgaris ELISA results from the foals across the study. Top graph presents the results from the foals, whereas the bottom graph presents the ratios between ELISA results from foals at each time point and their dams measured at the week of parturition. Y-error bars represent 95\% confidence intervals

the majority of shedding ended by 14 weeks of age. Colts shed higher numbers of eggs during peak shedding, but fillies shed for a longer duration (Fig. 3); however, this was not statistically significant.

\section{Coproculture}

Coproculture results are presented in Fig. 1 and Table 1. Table 2 presents the results of the McNemar test for comparisons between the coproculture and PCR results. Overall, the adult horses tested positive for $S$. vulgaris in $68.3 \%$ of the coprocultures analyzed. There were no statistical associations between $S$. vulgaris larval counts or percentage and time points or seasons; however, horses in the 12-18 year-old group shed higher total $S$. vulgaris compared to the 7-11 year-old group $(P<0.0001)$.

\section{Strongylus vulgaris $\mathrm{qPCR}$}

The PCR results are presented in Fig. 1 and Table 1. Table 2 presents the results of the McNemar test for comparisons between the coproculture and PCR 
Table 1 The number of adult horses testing positive and negative for Strongylus vulgaris by larval culture and PCR across the 26 time points in the study

\begin{tabular}{|c|c|c|c|c|}
\hline \multirow[t]{2}{*}{ Sample date } & \multicolumn{2}{|c|}{ Larval culture } & \multicolumn{2}{|l|}{$P C R$} \\
\hline & Positive & Negative & Positive & Negative \\
\hline Jan 1 & 13 & 6 & 15 & 4 \\
\hline $\operatorname{Jan} 23$ & 14 & 4 & 14 & 4 \\
\hline Feb 7 & 15 & 4 & 17 & 2 \\
\hline Feb 21 & 15 & 4 & 18 & 1 \\
\hline Mar 7 & 15 & 4 & 17 & 2 \\
\hline Mar 21 & 14 & 4 & 13 & 5 \\
\hline Apr 2 & 16 & 3 & 18 & 1 \\
\hline Apr 18 & 17 & 2 & 18 & 0 \\
\hline May 2 & 14 & 5 & 14 & 3 \\
\hline May 16 & 13 & 5 & 11 & 7 \\
\hline May 30 & 9 & 10 & 16 & 3 \\
\hline Jun 12 & 15 & 4 & 15 & 4 \\
\hline Jun 26 & 13 & 5 & 15 & 3 \\
\hline Jul 11 & 14 & 4 & 11 & 6 \\
\hline Jul 25 & 13 & 5 & 16 & 2 \\
\hline Aug 8 & 13 & 4 & 14 & 4 \\
\hline Aug 22 & 9 & 9 & 17 & 1 \\
\hline Sep 5 & 13 & 5 & 14 & 3 \\
\hline Sep 17 & 3 & 14 & 15 & 2 \\
\hline Oct 3 & 8 & 9 & 14 & 3 \\
\hline Oct 17 & 11 & 5 & 16 & 0 \\
\hline Oct 31 & 10 & 7 & 12 & 5 \\
\hline Nov 14 & 12 & 6 & 16 & 2 \\
\hline Nov 28 & 14 & 4 & 14 & 4 \\
\hline Dec 13 & 7 & 10 & 15 & 2 \\
\hline Dec 19 & 12 & 4 & 16 & 0 \\
\hline
\end{tabular}

Table 2 Comparison of the qualitative performance of the PCR and larval culture for detecting Strongylus vulgaris in the adult horses in the study

\begin{tabular}{llll}
\hline & \multicolumn{2}{l}{} & \\
\cline { 4 - 4 } & Positive & Negative & Total \\
\hline Larval culture & & 21 & \\
Positive & 294 & 46 & 315 \\
Negative & 100 & 67 & 146 \\
Total & 394 & 461 \\
\hline
\end{tabular}

The results of McNemar's test for paired proportions are-McNemar's test: $X^{2}=153.433, P<0.0001$

results. The qPCR detected $84.5 \%$ of samples as positive, which was statistically higher than the PCR. There were no statistical associations between mean Ct values and season, time point, age, or parturition status.

\section{Strongylus vulgaris ELISA}

ELISA results are presented in Fig. 1. There were no statistical differences in $S$. vulgaris ELISA values between seasons or collection points, or in regard to parturition or age in the adult horses.

Foal ELISA values are presented in Fig. 3. Antibody concentrations steadily decreased until 16 weeks of age, and then became highly variable and increased drastically, both as a percentage of the mare's ELISA value and as a percentage of the positive control $(P=0.0455)$.

\section{Worm counts in foals Cyathostomins}

Cyathostomin worm and encysted larval counts are presented in Table 3. Mucosal cyathostomin stages identified were LL3/L4s and counts ranged from 0 to 6000 larvae and were significantly lower in the younger foal group $(P=0.0303)$. In the group of older foals, mean larval counts were significantly higher in colts than in fillies $(P=0.0366)$.

\section{Strongylins}

Counts of non-cyathostomin parasites are presented in Table 4. Total migrating S. edentatus larval counts were highest in fillies $(P=0.0103)$ but did not vary significantly between the two age groups. Total migrating and luminal $S$. vulgaris counts were highest in colts 6-8 months of age, and ranged from 0 to 67 worms, with the majority occurring in the CMA (0-62). ELISA and FEC values were not statistically significantly associated with either counts of migrating or luminal stages of $S$. vulgaris in these foals.

\section{Other parasites}

Parascaris spp. counts were highest in colts 4-6 months of age, but no differences were found between fillies aged 4-6 months and 6-8 months (Table 4). Anoplocephala perfoliata counts were highest in foals 6-8 months of age and ranged from 0 to 43 worms.

\section{Discussion}

This study is the first comprehensive study of equine strongylid parasite transmission in North America. Furthermore, we have detailed the dynamics of S. vulgaris infection through coproculture, PCR, ELISA, and worm count data. Finally, this is the first study since 1974 to investigate the presence of PPR in horses.

Our results demonstrate a lack of seasonal differences in strongylid egg shedding among the mature horses. As outlined in the introduction, this is in stark contrast to both historical and more recent studies, which collectively demonstrated clear seasonal differences [11, 
Table 3 Mean cyathostomin worm burdens in the two age groups of foals in the study

\begin{tabular}{|c|c|c|c|c|}
\hline Age group & Cecum & Ventral colon & Dorsal colon & Overall luminal counts \\
\hline \multicolumn{5}{|c|}{ Luminal cyathostomins } \\
\hline $4-6$ months & $144(142)$ & $2378(3706)$ & $1241(1192)$ & $3733(4925)$ \\
\hline $8-10$ months & $800(779)$ & $33,400(31,340)$ & $10,775(15,458)$ & $44,975(46,060)$ \\
\hline \multicolumn{5}{|c|}{ Encysted cyathostomins } \\
\hline $4-6$ months & $1611(1799)$ & $1278(1277)$ & $444(768)$ & 3333 (3029) \\
\hline $8-10$ months & 6125 (4990) & 3875 (4768) & 375 (479) & $10,375(7687)$ \\
\hline
\end{tabular}

Standard deviation in parentheses

Table 4 Mean non-cyathostomin worm burdens in the two age groups of foals in the study

\begin{tabular}{lll}
\hline Age group & Migrating stages & Luminal stages \\
\hline Parascaris spp. & N/A & \\
4-6 months & N/A & $8(28)$ \\
8-10 months & N/A & \\
Anoplocephala perfoliata & N/A & $1(1)$ \\
4-6 months & & $10(16)$ \\
8-10 months & $11(9)$ & $0(0)$ \\
Strongylus vulgaris & $27(26)$ & $6(12)$ \\
4-6 months & & \\
8-10 months & $11(23)$ & $0(1)$ \\
Strongylus edentatus & $35(10)$ & $1(1)$ \\
4-6 months & & \\
8-10 months & &
\end{tabular}

Standard deviation in parentheses

18-22]. However, as mentioned previously, most of these previous studies were conducted in the UK, and since very few studies have been completed elsewhere, these patterns may differ substantially between regions and climates. Recent work with a cyathostomin computer model has suggested widely different transmission patterns between seasons and climates [42, 43], and it is therefore plausible that strongylid egg shedding patterns may differ between climates in a similar fashion. However, it should be acknowledged that the studied population may not be completely representative of managed horses in central Kentucky or elsewhere. Mean strongylid egg counts for the mature horses undulated around 1000 EPG throughout the study (Fig. 1), and this must be considered as unusually high for this age group. This can probably be largely explained by the lack of anthelmintic treatment since 1979, which undoubtedly has led to parasite dynamics very different from those of managed and routinely dewormed horses. Nonetheless, the aim of this study was to investigate parasite shedding seasonality as it occurs naturally in the absence of anthelmintic treatment, which justifies the choice of study population.
This study did not provide any evidence of a strongylid PPR (Fig. 1), which is in agreement with the observations reported by Duncan almost 50 years ago [11]. This is useful information for constructing parasite control programs in breeding operations and suggests that foaling mares do not need strongylid-directed treatments in addition to what is generally recommended for adult horses.

Shedding of S. vulgaris was found throughout the study, as reflected by both the coproculture and the PCR data (Fig. 1). Although statistically significant differences were not found between seasons, the data do resemble those described by Duncan in 1974 [11], with more shedding during spring months than at other times of the year. This can be explained by the duration of the $S$. vulgaris life-cycle, which includes a prepatent period of about 6 months. As suggested by Duncan [11], L3 larvae are ingested during the spring, summer, and early autumn, which means that many larvae will be migrating in the mesenteric arteries during the winter months and subsequently complete the life-cycle in the following spring. The shedding of larger numbers of $S$. vulgaris in the older age group has not been previously reported and may be due to differing immune responses between the two age groups. However, given the uneven distribution of horses between the two groups and the relatively small group size, this must be interpreted with caution. The serum ELISA values (Fig. 1) demonstrate a generally high S. vulgaris exposure in this herd, which is not surprising given the lack of anthelmintic treatment. The infection pressure is further evidenced by the $S$. vulgaris worm and larval counts in the necropsied foals (Table 4), which indicated that these infections are acquired early in life despite their diets consisting primarily of milk. Previous studies have demonstrated that it can take several months for antibody concentrations to reduce significantly following an effective anthelmintic treatment $[44,45]$, so even if $S$. vulgaris infection pressure fluctuates during the year, this would be unlikely to translate to a similar variation in antibody concentration. The foals displayed clear evidence of passive transfer of 
maternal anti-S. vulgaris antibodies and mounted their own antibody response beginning at about 20 weeks of age. A previous study from the same herd found a similar pattern [32], although substantial differences were noted between the two studies. In the study reported herein, the passively transferred maternal antibody concentrations were substantially higher, and the subsequent seroconversion occurred 4-5 weeks later compared to the study reported in 2014 [29]. Furthermore, Parascaris and Strongylus spp. burdens were considerably smaller in the foals in the present study compared to the previous findings [29]. It appears that infection pressures may have been different between the studies, and that weather patterns could represent one explanation of these observed differences. The foal/mare ELISA ratios (Fig. 3) demonstrated that while the concentration of the transferred maternal antibodies was a function of the serum antibody concentration of the corresponding dams, the subsequent antibody production was more variable between foals and, thus, less related to mare antibody concentrations.

In the foals, it is interesting to note the differences between the sexes, with colts shedding higher number of ascarid, S. westeri, and strongylid eggs overall (Fig. 2). This has not been previously demonstrated in this herd, and we are not aware of any such findings in other studies. In ruminants, males have been described to be more susceptible to gastrointestinal nematode infection than females [46], but a similar phenomenon is not widely described in horses. We have previously found fillies to harbor significantly higher numbers of Parascaris spp. in foals from this population [37], but that did not translate to a similar difference in ascarid egg counts. It should be noted that the colts excreted more strongylid eggs than the fillies at 2-8 weeks of age. As the shortest egg reappearance period reported for equine cyathostomins is 6 weeks [14], these findings must reflect coprophagy, and they suggest that colts may be more engaged in such activity than fillies. These results should be interpreted with caution given the limited number of foals and the uneven distribution of colts and fillies in the study, and these observations could have been affected by single outliers. It is worth noting that we found S. westeri egg shedding starting at 2 weeks and continuing until 14 weeks of age. This is in general agreement with Lyons' original description of the $S$. westeri life-cycle, where he described egg shedding to generally start at 8 days of age and peak at 11-12 days of age, with a proportion of foals remaining egg count-positive until 20-26 weeks of age [47]. These results also agree with a previous study which demonstrated that $S$. westeri egg counts were positive in foals up until 123 days (17 weeks) of age, after which all investigated foals had fecal egg counts of zero [48].

\section{Conclusions}

This study has provided novel information about parasite infection dynamics in horses kept in a Southeastern US climate. The results demonstrated a lack of seasonal differences of strongylid egg shedding and an absence of PPR in foaling mares but did suggest some seasonal pattern of S. vulgaris transmission. Furthermore, the results demonstrated the dynamics of passive transfer of maternal anti-S. vulgaris antibodies to foals and the establishment of several parasite categories during the first months of life. These results will be useful for understanding parasite epidemiology in a broader context, and emphasize the value of collecting this type of information from a variety of climatic settings. Certainly, this study demonstrated substantial differences from findings in previous studies primarily in the UK.

\section{Abbreviations}

FECs: Fecal egg counts; EPG: Eggs per gram; ELISA: Enzyme-linked immunosorbent assay; PCR: Polymerase chain reaction; IACUC: Institutional Animal Care and Use Committee; CMA: Cranial mesenteric artery.

\section{Acknowledgements \\ Not applicable.}

\section{Authors' contributions}

AES performed data collection and statistical analyses, and was a major contributor in writing of the manuscript. HPA assisted with data collection and statistical analyses, and contributed to the writing of the manuscript. TS assisted with data collection and aided in statistical analyses. MC assisted with data collection and aided in statistical analyses. JAS assisted with data collection and statistical analyses. HSG assisted with data collection. MKN served as principal investigator, developed the project idea, assisted with data collection, aided in statistical analyses, and was a major contributor to manuscript writing. All authors read and approved the final manuscript.

Funding

No outside funding was used in this study.

Availability of data and materials

The datasets used and/or analyzed during the current study are available from the corresponding author upon reasonable request.

\section{Declarations}

Ethics approval and consent to participate

This study was conducted under the University of Kentucky's IACUC, protocol \#2012-1046.

\section{Consent for publication}

Not applicable.

\section{Competing interests}

All authors declare no competing interests.

\section{Author details \\ ${ }^{1}$ School of Veterinary Medicine, Texas Tech University, Amarillo, TX, USA. ${ }^{2} \mathrm{Col}-$ lege of Veterinary Medicine, Auburn University, Auburn, AL, USA. ${ }^{3}$ College of Veterinary Medicine, Lincoln Memorial University, Harrogate, TN, USA. \\ ${ }^{4}$ Department of Animal Science, Eastern Kentucky University, Richmond, KY, USA. ${ }^{5}$ Department of Veterinary Science, Maxwell H. Gluck Equine Research Center, University of Kentucky, Lexington, KY, USA.}


Received: 15 December 2021 Accepted: 17 January 2022

Published online: 08 February 2022

\section{References}

1. Peregrine AS, Molento MB, Kaplan RM, Nielsen MK. Anthelmintic resistance in important parasites of horses: does it really matter? Vet Parasitol. 2014:201:1-8

2. Nielsen MK, Banahan M, Kaplan RM. Importation of macrocyclic lactone resistant cyathostomins on a US Thoroughbred farm. Int J Parasitol Drugs Drug Resist. 2020;14:99-104.

3. Kester W. Strongylus vulgaris - the horse killer. Mod Vet Pract. 1975:56:569-72.

4. Pihl T, Nielsen M, Olsen S, Leifsson P, Jacobsen S. Nonstrangulating intestinal infarctions associated with Strongylus vulgaris: clinical presentation and treatment outcomes of 30 horses (2008-2016). Equine Vet J. 2018:50:474-80.

5. Drudge $\mathrm{JH}$, Lyons ET. Control of internal parasites of the horse. J Am Vet Med Assoc. 1966;148:373-83.

6. Herd RP. The changing world of worms: the rise of the cyathostomes and the decline of Strongylus vulgaris. Comp Cont Educ Pract Vet. 1990;12:732-4.

7. Love S, Duncan J. Could the worms have turned? Equine Vet J. 1991;23:152-4

8. Nielsen MK, Mittel L, Grice A, Erskine M, Graves E, Vaala W, et al. AAEP parasite control guidelines. American Association of Equine Practitioners. www.aaep.org. Accessed 25 Mar 2013.

9. Rendle D, Austin C, Bowen M, Cameron I, Furtado T, Hodgkinson J, et al. Equine de-worming: a consensus on current best practice. UK-Vet Equine. 2019;3:1-14

10. European Scientific Counsel Companion Animal Parasites (ESCCAP). A guide to the treatment and control of equine gastrointestinal parasite infections, 2nd edition. https://www.esccap.org/uploads/docs/rtjqm u6t_0796_ESCCAP_Guideline_GL8_v7_1p.pdf.

11. Duncan J. Field studies on the epidemiology of mixed strongyle infection in the horse. Vet Rec. 1974;94:337-45.

12. Nielsen MK, Kaplan RM, Thamsborg SM, Monrad J, Olsen SN. Climatic influences on development and survival of free-living stages of equine strongyles: implications for worm control strategies and managing anthelmintic resistance. Vet J. 2007;174:23-32.

13. Duncan JL, Pirie HM. The life cycle of Strongylus vulgaris in the horse. Res Vet Sci. 1972;13:374-85.

14. Round MC. The prepatent period of some horse nematodes determined by experimental infection. J Helminthol. 1969;43:185-92

15. Gibson $T$. The effect of repeated anthelmintic treatment with phenothiazine on the faecal egg counts of housed horses, with some observations on the life cycle of Trichonema spp. in the horse. J Helminthol. 1953;27:29-40

16. Smith HJ. Strongyle infections in ponies I. Response to intermittent thiabendazole treatment Can J Comp Med 1976:40:327-33.

17. Smith HJ. Strongyle infections in ponies II. Reinfection of treated animals. Can J Comp Med. 1976:40:334-40.

18. Poynter D. Seasonal fluctuation in the number of strongyle eggs passed by horses. Vet Rec. 1954;66:74-8.

19. Wood ELD, Matthews JB, Stephenson S, Slote M, Nussey DH. Variation in fecal egg counts in horses managed for conservation purposes: individual egg shedding consistency, age effects and seasonal variation. Parasitology. 2013:140:115-28.

20. Lester HE, Morgan ER, Hodgkinson JE, Matthews JB. Analysis of strongyle egg shedding consistency in horses and factors that affect it. J Equine Vet Sci. 2018:60:113-9.

21. Tydén E, Jansson A, Ringmark S. Parasites in horses kept in a 2.5 yearround grazing system in Nordic conditions without supplementary feeding. Animals. 2019;9:1156.

22. Nielsen MK, Gee EK, Hansen A, Waghorn T, Bell J, Leathwick DM. Monitoring equine ascarid and cyathostomin parasites: evaluating health parameters under different treatment regimens. Equine Vet J. 2021;53:902-10.
23. Chapman MR, French DD, Klei TR. Prevalence of strongyle nematodes in naturally infected ponies of different ages and during different seasons of the year in Louisiana. J Parasitol. 2003;89:309-14.

24. Relf VE, Morgan ER, Hodgkinson JE, Matthews JB. Helminth egg excretion with regard to age, gender and management practices on UK Thoroughbred studs. Parasitology. 2013;140:641-52.

25. Adams AA, Betancourt A, Barker VD, Siard MH, Elzinga S, Bellaw JL, et al Comparison of the immunologic response to anthelmintic treatment in old versus middle-aged horses. J Equine Vet Sci. 2015:35:873-81.

26. Debeffe L, McLoughlin PD, Medill SA, Stewart K, Andres D, Shury T, et al. Negative covariance between parasite load and body condition in a population of feral horses. Parasitology. 2016;143:983-97.

27. Gibbs HC. Hypobiosis and the periparturient rise in sheep. Vet Clin North Am Food Anim. 1986:2:345-53.

28. Jansen J. The peri-parturient rise in sheep. Faecal worm egg counts in normal and late lambing ewes. Vet Q. 1987;9:97-102.

29. Nielsen MK, Vidyashankar AN, Gravatte HS, Bellaw J, Lyons ET, Andersen UV. Development of Strongylus vulgaris-specific serum antibodies in naturally infected foals. Vet Parasitol. 2014;200:265-70.

30. Lyons ET, Drudge JH, Tolliver SC. Prevalence of some internal parasites found (1971-1989) in horses born on a farm in Central Kentucky. J Equine Vet Sci. 1990;10:99-107.

31. Noel ML, Scare JA, Bellaw JL, Nielsen MK. Accuracy and precision of Mini-FLOTAC and McMaster techniques for determining equine strongyle egg counts. J Equine Vet Sci. 2017:48:182-7.

32. Bellaw JL, Nielsen MK. Evaluation of Baermann apparatus sedimentation time on recovery of Strongylus vulgaris and S. edentatus third stage larvae from equine coprocultures. Vet Parasitol. 2015;211:99-101.

33. Russell AF. The development of helminthiasis in thoroughbred foals. J Comp Pathol. 1948;58:107-27.

34. Scare JA, Slusarewicz P, Noel ML, Wielgus KM, Nielsen MK. Evaluation of accuracy and precision of a smartphone based automated parasite egg counting system in comparison to the McMaster and Mini-FLOTAC method. Vet Parasitol. 2017;247:85-92.

35. Nielsen MK, Peterson DS, Monrad J, Thamsborg SM, Olsen SN, Kaplan RM. Detection and semi-quantification of Strongylus vulgaris DNA in equine faeces by real-time quantitative PCR. Int J Parasitol. 2008:38:443-53.

36. Andersen UV, Howe DK, Dangoudoubiyam S, Toft N, Reinemeyer CR, Lyons ET, et al. rSvSXP: a Strongylus vulgaris antigen with potential for prepatent diagnosis. Parasites Vectors. 2013;6:84.

37. Fabiani JV, Lyons ET, Nielsen MK. Dynamics of Parascaris and Strongylus spp. parasites in untreated juvenile horses. Vet Parasitol. 2016;230:62-6.

38. Donoghue EM, Lyons ET, Bellaw JL, Nielsen MK. Biphasic appearance of corticated and decorticated ascarid egg shedding in untreated horse foals. Vet Parasitol. 2015;214:114-7

39. Nielsen MK, Baptiste KE, Tolliver SC, Collins SS, Lyons ET. Analysis of multiyear studies in horses in Kentucky to ascertain whether counts of eggs and larvae per gram of feces are reliable indicators of numbers of strongyles and ascarids present. Vet Parasitol. 2010;174:77-84.

40. Nielsen MK, Martin AN, Scare JA, Steuer AE. Precision and spatial variation of cyathostomin mucosal larval counts. Vet Parasitol. 2021;290: 109349.

41. Nielsen MK, Wang J, Davis R, Bellaw JL, Lyons ET, Lear TL, et al. Parascaris univalens - a victim of large-scale misidentification? Parasitol Res. 2014:113:4485-90.

42. Nielsen MK, Sauermann CW, Leathwick DM. The effect of climate, season, and treatment intensity on anthelmintic resistance in cyathostomins: a modelling exercise. Vet Parasitol. 2019;269:7-12.

43. Sauermann CW, Leathwick DM, Lieffering M, Nielsen MK. Climate change is likely to increase the development rate of anthelmintic resistance in equine cyathostomins in New Zealand. Int J Parasitol Drugs Drug Resist. 2020;4:73-9.

44. Nielsen MK, Vidyashankar AN, Bellaw J, Gravatte HS, Cao X, Rubinson EF, et al. Serum Strongylus vulgaris-specific antibody responses to anthelmintic treatment in naturally infected horses. Parasitol Res. 2015;114:445-51.

45. Nielsen MK, Scare J, Gravatte HS, Bellaw JL, Prado JC, Reinemeyer CR Changes in serum Strongylus vulgaris-specific antibody concentrations in response to anthelmintic treatment of experimentally infected foals. Front Vet Sci. 2015:2:17. 
46. Barger IA. Influence of sex and reproductive status on susceptibility of ruminants to nematode parasitism. Int J Parasitol. 1993;23:463-9.

47. Lyons ET, Drudge JH, Tolliver SC. On the life cycle of Strongyloides westeri in the equine. J Parasitol. 1973;59:780-7.

48. Miller FL, Bellaw JL, Lyons ET, Nielsen MK. Strongyloides westeri worm and egg counts in naturally infected young horses. Vet Parasitol. 2017;15:1-3.

\section{Publisher's Note}

Springer Nature remains neutral with regard to jurisdictional claims in published maps and institutional affiliations.

- fast, convenient online submission

- thorough peer review by experienced researchers in your field

- rapid publication on acceptance

- support for research data, including large and complex data types

- gold Open Access which fosters wider collaboration and increased citations

- maximum visibility for your research: over $100 \mathrm{M}$ website views per year

At $\mathrm{BMC}$, research is always in progress.

Learn more biomedcentral.com/submissions 